Developments in the understanding of laser-plasma interactions, and of the necessary diagnostic techniques, are equally impressive. Various groups have experimentally investigated the absorption of laser light at wavelengths $(i)$ of $1 / 4,1 / 2,1$ and $10 \mu \mathrm{m}$, and at intensities $(I)$ within at least part of the range $I=10^{10}-10^{16}$ $\mathrm{W} / \mathrm{cm}^{2}$; there now appears to be universal agreement that strong densityprofile modifications are induced by radiation pressure effects when $\left(/ \lambda^{2}\right)$ $\sim 10^{15}\left(\mathrm{~W} / \mathrm{cm}^{2}\right)(\mu \mathrm{m})^{2}$, and that resonance absorption increases the total absorption coefficient at the longer wavelengths signficantly. Related measurements suggest that much of the absorbed radiant energy is then converted to hot, non-thermal, electrons. Developments in two and threedimensional soliton theory, and in analytic modelling of strong turbulence by the Russian school, are equally impressive.

The main topic for controversy appears to be the computer optimisation of target designs, where the avoidance of unwanted core preheating by the "hot" electrons and of possible deviations from the desired symmetry of implosion (due to Rayleigh-Taylor instabilities) poses significant modelling problems in the hydrodynamic codes. The US prefer "thick" (lower aspect ratio) doubleshell designs to obviate both of these problems.

Our hosts are to be congratulated on arranging a particularly topical meeting, on the excellence and individuality of the oral translation facilities, and on the warmth of their hospitality, which more than compensated for external temperatures of $<243 \mathrm{~K}$ ! The next meeting will be organised by the DDR Physical Society, and will probably be held in December 1979 at Leipzig.

\section{J. Spalding} (Culham Laboratory)

\title{
EPS Scholarships for 1979/1980
}

\section{Second List - Federal Republic of Germany}

EPS Divisions, Sections and Group
Astronomy and Astrophysics Division
Solar Section
Atomic Physics Division
Atomic Spectroscopy Section
Chemical Physics
Electronic and Atomic Collisions
Molecular Physics
Computational Physics Group
Condensed Matter Division
Low Temperature Section
Macromolecular Physics
Magnetism
Metals
Semiconductors and Insulators
Surface and Interface
High Energy \& Particle Physics Division
Nuclear Physics Division
Plasma Physics Division
Quantum Electronics Division

Further to the list of scholarships available in Poland, Romania and Switzerland, published in the December issue of Europhysics News, EPS can now announce the availability of five scholarships in the Federal Republic of Germany.

These are at:

- the Deutsches Elektronen-Synchrotron centre DESY, Hamburg

- the Hahn-Meitner-Institut für Kernforschung, Berlin (2) and

- the Kernforschungszentrum, Karlsruhe (2)

Further details are given below.

\section{DESY}

DESY is the principal national and state high energy physics laboratory that has specialized in electron machines. A $7 \mathrm{GeV}$ synchrotron was followed by DORIS, the $3+3 \mathrm{GeV}$ $\mathrm{e}^{+} \mathrm{e}^{-}$rings and PETRA the $19+19$ $\mathrm{GeV} \mathrm{e}^{+} \mathrm{e}-$ rings where luminosity has just reached $10^{30} \mathrm{~cm}^{-2} \mathrm{~s}^{-1}$. Associated with DORIS is a synchrotron radiation facility.

The Scholarship is for experimental or theoretical work in elementary particle physics connected with the use of DORIS or PETRA. Remuneration will be from 3000 to $4000 \mathrm{DM} /$ month according to qualifications. Normal travel to Hamburg paid by the Centre.

\section{Hahn-Meitner-Institute}

The Institute is a State funded centre of fundamental nuclear research, specializing in heavy ion physics, radiation and photochemistry, solid state research and nuclear chemistry. Principal experimental machines include a $5 \mathrm{MW}$ reactor, a $200 \mathrm{MeV}$ heavy ion accelerator and several electron accelerators.
Scholarships are for post-doctoral work in the following fields:

1. Nuclear physics and heavy ion research (Profs. Eichler, Lindenberger and von Oertzen)

2. Nuclear sold state physics (Profs, Dachs, Vogl, Wollenberger)

3. Radiation Chemistry (Prof. Henglein)

The salary paid will be between 2600 and $3500 \mathrm{DM} /$ month depending on experience and responsibilities. Normal travel costs will be paid by the Institute.

\section{The Karlsruhe Research Centre}

The Karlsruhe Laboratory is one of the two national nuclear research establishments with a very broad programme of research on fundamental and applied topics, centred round a series of research and experimental reactors. The Laboratory is also host to the European Transuranium Institute.

Scholarships are for post-doctoral work in the following fields:

(Division headed by Prof. W. Klose)

1. Solid state physics

2. Nuclear physics

3. Nuclear chemistry

Remuneration is at the rate of 1800 $\mathrm{DM} /$ month plus $1000 \mathrm{DM}$ for the first month and help with the purchase of books. Travelling is not reimbursed.

Applications should be made to the EPS Secretariat. It is helpful also if some direct contact is established between the applicant and the professor under whom he will be working. STOP PRESS: A further Scholarship has been offered by the Gesellschaft für Schwerionenforschung in Darmstadt for research with the heavy ion accelerator UNILAC, in cooperation with an existing group. Details next issue.

Europhysics News is the official journal of the European Physical Society that comprises $28 \mathrm{Na}$ tional Societies, Academies and Groups, over 3000 Individual Ordinary Members and 30 Associate Members. Governing bodies of EPS are the General Meting. Council and an elected ExecGeneral Moeting, Counch and an elected ExecEPS promotes the collaboration of physicist throughout Europe and encourages all aspects of international exchange in physics. EPS award scholarships for research and studies in different countries. EPS publishes, in addition to Europhysics News, Europhysics Conference Abstracts, Europhysics Education News and the Proceedings of rophysics Educat its General Conferences. Individual Ordinary Members receive Europhysics News (subscription for non-Members: $75 \mathrm{Sw}$. Fr./a), substantial rebates on many publications and pay reduced fees at conferences. Application for membership is made through the permanent Secretariat which is located in Geneva. Annual subscription for members of a National Society is $28 \mathrm{Sw} . \mathrm{Fr}$.
Editor : E.N. Shaw

Meetings Compilation: W.S. Newman

Editorial Board :

G.J. Béné, G.R. Macleod, A. Maeder,

J. Muller, D. Pohl, J.A. Schwarzmuller Secretariat.

Address: EUROPEAN PHYSICAL SOCIETY P.O. Box 69 CH-1213 Petit-Lancy 2 Switzerland

Telephone : Geneva (22) 931130

Telex : 23455 alarm ch

Cables : euraphys genève

Printed by : Ed. Cherix ef Fllanosa SA CH-1260 Nyon, Swltzerland
Editorial and Advertising Office at the EPS 